\title{
The improvement of the skin quality with the use of PLLA
}

\begin{abstract}
When a patient is seeking PLLA treatment, the focus is usually on compensating for different losses she or he may have in regards to volumization and laxity. However, the improvement of skin quality is one of the unexpected benefits invariably seen in final results. The objective of this manuscript is to call attention to this aspect, to understand how it occurs and to demonstrate how this can be obtained using one specific technique, among many others.
\end{abstract}

Keywords: PLLA, skin laxity, skin quality, rejuvenation
Volume 2 Issue 2 - 2018

\section{Luiz Eduardo Avelar, Camila Eduardo \\ Cazerta \\ Department of Anthropology and Plastic Surgery, Brazil}

Correspondence: Luiz Eduardo Avelar, Department of Anthropology and Plastic Surgery, Police Department of Minas Gerais, Avenida do Contorno, 4852, 30I I0-100 Belo Horizonte-MG, Brazil, Email contato@luizeduardoavelar.com.br

Received: June 08, 2017| Published: March 08, 2018

\section{Introduction}

There are three main recommendations for the use of Sculptra: bone resorption, fat loss and skin laxity; at which layer of the face and at what plane PLLA is administered depends on the patient's condition. In respect to bone resorption, injections need to be applied very deeply, close to the bone, whereas, in the case of deciduous fat compartments or fat deflation, the PLLA delivery needs to be into the subcutaneous layer. The volumization that results from the product is enough to compensate for bone and fat loss. ${ }^{1-3}$ However, concerning skin laxity, the opposite occurs - as PLLA needs to be applied just underneath the skin, into the subdermal plane, with needles or cannulas, but with no fat in between. It is in this layer that the best skin quality outcomes can be obtained, which is the purpose of this manuscript. ${ }^{4,5}$

Whenever PLLA (Poly-L-Lactic Acid) is injected into a subdermal plane there is an improvement to skin quality which is characterized by three signs. The first being distinct glow-luminosity caused by the hydration of the treated skin, giving the impression of a healthy, youthful and well preserved skin. Another benefit is the correction of skin atrophy - indeed, an increase in skin thickness can generally be observed when treating the elderly. Furthermore, skin laxity is usually corrected seeing as there tends to be an adherence of the skin to the deeper planes of the face. This is understandable due to the production of collagen fibers resulting from the PLLA applications. Nonetheless, it is still necessary to study and better comprehend the mechanisms of action involved.

\section{Mechanism of action6}

As soon as PLLA is injected under the skin, be it with a needle or cannula, during a period of up to 3 days, a significant amount of inflammatory cells migrate to the treated area and amidst all the leukocytes, a very important intravascular cell, named monocyte, migrates to the region and is then named macrophage. However, as this powerful cell is not big enough to phagocyte particles ranging from 40 to $63 \mathrm{~m}$, like those found with PLLA, more and more macrophages, are sent to the location. Once they are very close to one another, these cells start to join to each other and make up another kind of inflammatory cell, called a Multinuclear Giant Cell. This occurs, in average, 10 days after the injection._At this moment, a protein, named Cytokine, is produced by the Multinuclear Giant Cells_inducing a fibroblast migration to the area. After 3 weeks, it is possible to observe collagen fiber production. This answers the use of Sculptra for the treatment of laxity.?

Nonetheless, it is essential to remind ourselves that these fibroblast cells also produce elastic fibers and glycosaminoglycans. One of these glycosaminoglycans is the well-known, Hyaluronic Acid, a polysaccharide molecule responsible for the formation of gelatinous matrix along with the hydration of cutaneous tissue.

Therefore, whenever PLLA treatment is being used, besides the improvement of laxity there is an increase in the thickness and hydration of the skin.

\section{Personal technique}

The treatment comprises of, in average, 3 sessions with an interval ranging from 45 to 60 days. Up to two vials are used per session $-24 \mathrm{~h}$ prior to the treatment, $7 \mathrm{ml}$ of sterile water is used to reconstitute the vial components and at the moment of the application, a further $2 \mathrm{ml}$ of lidocaine is added to the solution.

PLLA for skin quality improvement is used subdermally, never intradermically, which could cause some adverse effects. Although the use of a needle is a good option for injection, the author nowadays prefers the use of cannula. Safety, less pain and less entry points are some of the reasons for this choice. With a needle, a puncture is done under the zygomatic arch where a $23 \mathrm{G}$ cannula is used to inject the product into the malar, submalar region and the temporal fossa. One or two other entry points are done at the angle of the mandible and at the lateral of the chin (the latter not being used with every patient). The posterior region of the mandible and also the pre-jowl area are treated, avoiding any deposit at the jowl that could worsen the problem (Figures 1) (Figures 2). The volume used depends on 
the patient's needs - each patient has to be evaluated per session; however, the minimum amount used is $1 \mathrm{vial} /$ session. Massage after treatment is required.

Patients are followed-up after 18 months, when one additional session is required, in other to avoid the total absorption of the produced collagen fibers.

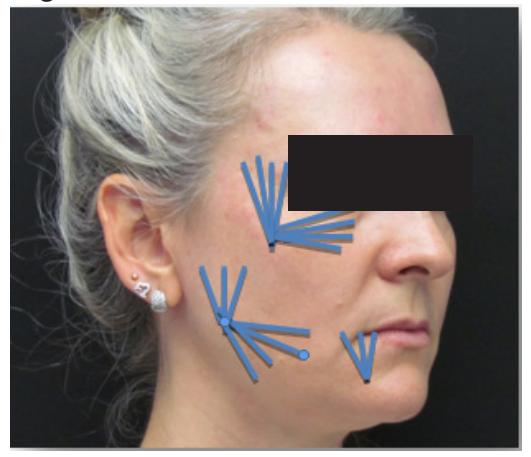

Figure I For superficial application, only, two or three entry points are used for cannula injection- the treatment at lateral of chin is not always required.

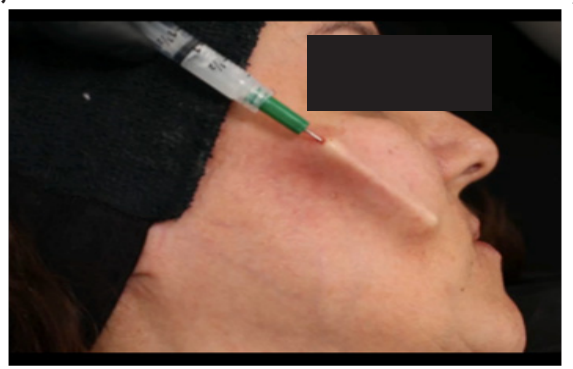

Figure 2 Injection of PLLA with cannula, superficially. Notice there is no fat between the skin and cannula.

\section{Conclusion}

Despite PLLA being recommended for different applications - bone resorption, fat loss and skin laxity - there is a consistent improvement to skin quality after treatment (Figures 3-5). Nonetheless, not only is it essential to understand the mechanism of action of PLLA but also
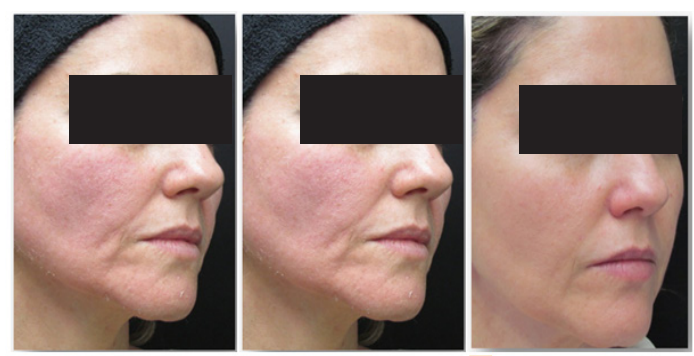

determining the plane of injection.

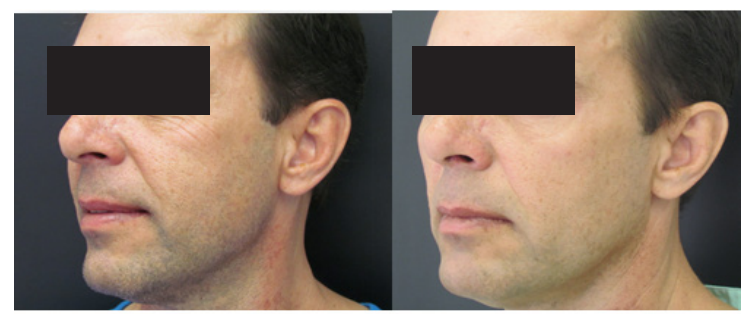

Figure 3 Before and after 47 years old woman. Result 3 months after the third session - I vial/ session. Improvement of skin laxity and quality.

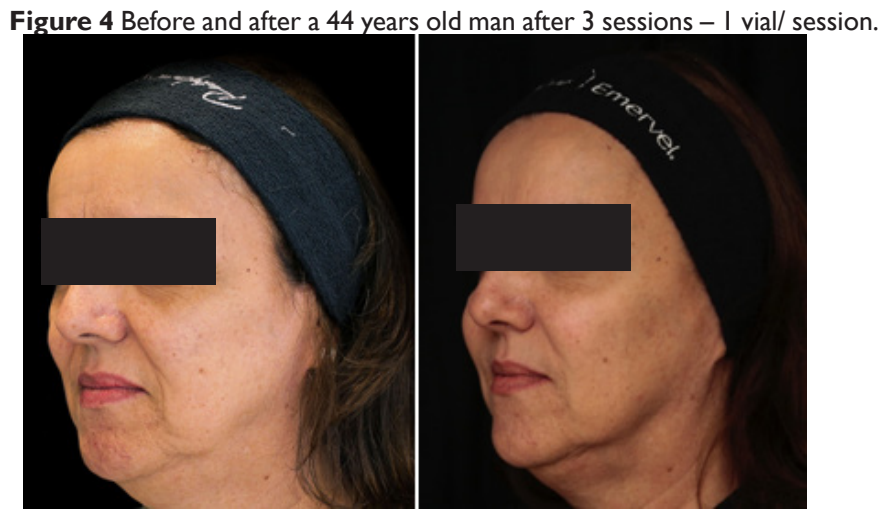

Post treatment photo taken 3 months after the third session.

Figure 5 Fifty-seven years old woman, with 3 sessions of - I vial/session. Observe the correction of deciduous fat compartment and the improvement of skin quality, one month after the third session.

\section{Acknowledgements}

None.

\section{Conflicts of interest}

The authors declared that there are no conflicts of interest.

\section{References}

1. Fitzgerald R, Vleggaar D. Facial Volume Restauration of the aging Fce with Poly-L-Lactic Acid. Dermatol Ther. 2011;24(1):2-27.

2. Filho CDSM, Santos TC, Rodrigues APLJ, et al. Poly-L-Lactic Acid: a biostimulating agent. Surg Cosmet Dermatol. 2013;5(4):345-350.

3. Lowe NJ. Opptimizing Poly-L-Lactic Acid use. $J$ Cosmet Laser Ther. 2008;10(1):43-46.

4. Goldman MP. Cosmetic use of Poly-L-Lactic acid: my technique for success and minimizing complications. Dermatol Surg. 2011;37(5):688-693.

5. Lam SM, Azizzedh B, Graivier M. Injectable Poly-L-Lactic acid (Sculptra): technical considerations in soft tissue contouring. Plast Reconstr Surg. 2006;219(3 Supp):55S-63S.

6. Lacombe V. Sculptra: a stimulatory filler. Facial Pastic Surg. 2009;25(2):95-99.

7. Sherman RN. Sculptra: the new three-dimensional filler. Clin Plast Surg. 2006;33(4):539-550. 